\title{
Salivary biomarkers for diagnosis of systemic diseases and malignant tumors. A systematic review
}

\author{
Marco Meleti ${ }^{1}$, Diana Cassi ${ }^{2}$, Paolo Vescovi ${ }^{3}$, Giacomo Setti ${ }^{4}$, Thelma A. Pertinhez ${ }^{5}$, Margherita Eleonora \\ Pezzi ${ }^{6}$
}

${ }^{1}$ DDS, PhD. Researcher in Oral Medicine and Surgery. Centro Universitario di Odontoiatria, Department of Medicine and Surgery, University of Parma, Italy

${ }^{2}$ DDS, PhD, Spec. Orth.. Adjunct Professor. Department of Surgical, Medical, Dental and Morphological Science with interest in Transplant Oncological and Regenerative Medicine, University of Modena and Reggio Emilia, Italy

${ }^{3}$ DDS, MS, PhD. Spec. Or. Surg., Associate Professor of Oral Medicine and Surgery. Centro Universitario di Odontoiatria, Department of Medicine and Surgery, University of Parma, Italy

${ }^{4}$ DDS, PhD student. Centro Universitario di Odontoiatria, Department of Medicine and Surgery, University of Parma, Italy

${ }^{5} \mathrm{PhD}$. Associate Professor of Biochemistry. Department of Medicine and Surgery, University of Parma and Transfusion Medicine Unit, Azienda USL - IRCCS di Reggio Emilia, Italy

${ }^{6}$ DDS. Postgraduate student. Centro Universitario di Odontoiatria, Department of Medicine and Surgery, University of Parma, Italy

Correspondence:

Centro Universitario di Odontoiatria

Via Gramsci 14. 43126, Parma, Italy

margherita.pezzi@gmail.com

Received: 28/07/2019

Accepted: 06/08/2019
Meleti M, Cassi D, Vescovi P, Setti G, Pertinhez TA, Pezzi ME. Salivary biomarkers for diagnosis of systemic diseases and malignant tumors. A systematic review. Med Oral Patol Oral Cir Bucal. 2020 Mar 1;25 (2):e299-310.

\begin{tabular}{l} 
Article Number:23355 http://www.medicinaoral.com/ \\
C Medicina Oral S. L. C.I.F. B 96689336 - pISSN 1698-4447 - eISSN: 1698-6946 \\
eMail: medicina@medicinaoral.com \\
Indexed in: \\
Science Citation Index Expanded \\
Journal Citation Reports \\
Index Medicus, MEDLINE, PubMed \\
Scopus, Embase and Emcare \\
Indice Médico Español \\
\hline
\end{tabular}

\begin{abstract}
Background: Saliva evaluation could be a possible alternative to blood and/or tissue analyses, for researching specific molecules associated to the presence of systemic diseases and malignancies.

The present systematic review has been designed in order to answer to the question "are there significant associations between specific salivary biomarkers and diagnosis of systemic diseases or malignancies?”.

Materials and Methods: The Preferred Reporting Item for Systematic Reviews and Meta-analysis (PRISMA) statement was used to guide the review.

The combinations of "saliva" and "systemic diseases" or "diagnosis" or "biomarkers" or "cancers" or "carcinoma" or "tumors", were used to search Medline, Scopus and Web of Science databases. Endpoint of research has been set at May 2019.

Studies were classified into 3 groups according to the type of disease investigated for diagnosis: 1) malignant tumors; 2) neurologic diseases and 3) inflammatory/metabolic/cardiovascular diseases.

Assessment of quality has been assigned according to a series of questions proposed by the National Institute of Health. Level of evidence was assessed using the categories proposed in the Oxford Center for Evidence-Based medicine (CEMB) levels for diagnosis (2011).
\end{abstract}


Results: Seventy-nine studies met the inclusion and exclusion criteria. Fifty-one (64\%) investigated malignant tumors, 14 (17.5\%) neurologic and 14 (18.5\%) inflammatory/cardiovascular/metabolic diseases.

Among studies investigating malignant tumors, $12(23.5 \%)$ were scored as "good" and 11 of these reported statistically significant associations between salivary molecules and pathology. Two and 5 studies were found to have a good quality, among those evaluating the association between salivary biomarkers and neurologic and inflammatory/ metabolic/cardiovascular diseases, respectively.

Conclusions: The present systematic review confirms the existence of some "good" quality evidence to support the role of peculiar salivary biomarkers for diagnosis of systemic diseases (e.g. lung cancer and EGFR).

Key words: Salivary diagnostics, biomarkers, systemic diseases, malignant tumors, early diagnosis.

\section{Introduction}

Currently, one of the most relevant targets of medicine and healthcare is early diagnosis. Detecting a disease at an early stage may improve the possibility of success of treatment, prevent complications and enhance prognosis and quality of life (1).

The concept of "point-of-care diagnosis" includes a field of investigation that explores technologies allowing patients and health providers to gain actionable medical information rapidly and conveniently (1).

The term "precision medicine" refers to the uses of molecular profiles, genomic, transcriptomic, proteomic and metabolomic, to adapt a personalized therapeutic strategy for peculiar patients: a. in the right moment, $b$. to determine the predisposition to diseases, and c. to provide timely and targeted prevention (2).

The combination of such profiles and the identification of biomarkers is leading to the development of new technologies, based on easy and non-invasive methods to collect diagnostic human specimens, possibly with a high specificity and sensitivity and customized on single patient.

In the last ten years, research has focused on the use of biomarkers in a previously poorly investigated human fluid: saliva.

Saliva is a fluid constantly produced by salivary glands and It has a complex molecular composition. Saliva is abundantly delivered in the oral cavity, its collection being simple and non-invasive. Moreover, transportation and storing are easy. For such reasons, saliva evaluation could be considered as a possible alternative to blood and/or tissue analyses, for researching specific molecules (DNA, RNA, proteins and metabolites) associated to the presence of systemic diseases and malignancies (3).

The present systematic review has been designed in order to answer to the question "are there significant associations between specific salivary biomarkers and diagnosis of systemic diseases or malignancies?", formulated according to the "Patient-InterventionComparison-Outcome" (PICO) worksheet.

\section{Material and Methods}

The Preferred Reporting Item for Systematic Reviews and Meta-analysis (PRISMA) statement was used to guide this systematic review (98).

- Search strategy

The combinations of "saliva" and "systemic diseases" or "diagnosis" or "biomarkers" or "cancers" or "carcinoma" or "tumors", have been used for searching Medline, Scopus and Web of Science databases. Only English literature was searched. We considered articles published after 2000 (endpoint of research has been set at May 2019). Periodic screening of the databases was performed, between September 2017 and May 2019.

- Inclusion and exclusion criteria

Only papers reporting details on salivary sampling and biochemical analysis were included. Papers selected were primarily focused on the use of saliva for diagnostic purposes. We only included studies performed on humans, detailing the disease of patients and providing precise information on diagnosis. Studies reporting data on at least 5 patients were included.

Case reports, conference proceedings and personal communication were excluded.

Studies dealing with biomarkers evaluated for therapy, prognosis or staging of systemic diseases were not included.

We excluded researches specifically investigating salivary biomarkers in patients with systemic diseases with oral, oropharyngeal and esophageal involvement. Such a choice was taken in order to exclude presence of pathologies in the proximity of the site of saliva collection, thus avoiding confounding factors (e.g. contamination with peripheral molecules not originally presents in the salivary secrete).

Papers dealing with systemic microbial infections, hormones, drug dosage, were further excluded.

We excluded studies specifically reporting on biochemical methods, technological aspects, devices used or proposed for saliva evaluation or detection of specific molecules.

The criteria are summarized in Table 1. 
Table 1: Inclusion and exclusion criteria.

\begin{tabular}{|c|c|}
\hline INCLUSION CRITERIA & EXCLUSION CRITERIA \\
\hline $\begin{array}{l}\text { 1) The study should provide information on: } \\
\text { Saliva sample } \\
\text { Biochemical analysis } \\
\text { Biomarkers used for diagnostic purpose } \\
\text { 2) Human subjects } \\
\text { 3)Precise information on diseases investigated } \\
\text { 4) Study population on at least } 5 \text { patients }\end{array}$ & $\begin{array}{l}\text { 1) Case reports, conference proceedings and personal communication } \\
\text { 2) Biomarkers used for therapeutic, prognosis or staging purpose } \\
\text { 3) Diseases with oral, oropharyngeal and esophageal involvement } \\
\text { 4) Papers dealing with microbial infections, hormones, drug dosage } \\
\text { 5) Studies on animal model or in vitro } \\
\text { 6) Studies on biochemical methods, technological aspects, devices }\end{array}$ \\
\hline
\end{tabular}

\section{- Data extraction}

Titles and abstracts were screened by two independent investigators. Equivocal titles/abstracts were included for full-text evaluation.

Reviews of literature addressing the topic of salivary biomarkers and diagnosis of systemic diseases and malignant tumors were carefully read and all references were screened in order to include papers possibly not selected through the entry terms used within the databases. Other relevant literature was identified from the reference lists of the retrieved articles.

Information extracted from each study were summarized in an Excel $^{\circledR}$ table and they included title, citation date (authors, publication year), pathology investigated, type of biomarkers, device used to analyze the sample, results and presence of statistically significant association.

- Data analysis

Studies were assessed for overlapping series of patients on the basis of the recruitment Centre and period. Wherever multiple studies reported the same set of data in fully detectable overlapping series of patients, only the most recent or the most complete series was included in the review.

Studies were classified into 3 groups according to the type of disease investigated for diagnosis: 1) malignant tumors; 2) neurologic diseases and 3) inflammatory/ metabolic/cardiovascular diseases.

- Quality assessment and critical appraisal

Assessment of quality has been assigned according to a series of questions proposed by the National Institute of Health (NIH) for each typology of study (controlled intervention studies, systematic reviews and meta-analysis, observational cohort and cross-sectional studies, case control studies, before-after studies with no control group, case series studies) (4).

Critical appraisal has been summarized through assignation of a value ranging from 0 to $100 \%$ to each of the study selected, based on the percentage of "yes" choices on the overall number of answers given. Furthermore, the number of patients enrolled in each study was taken into consideration.
Studies with a percentage of quality ranging from 80 to $100 \%$ were defined as "good". Studies with a quality ranging between 50 and $80 \%$ were defined as "fair" and studies scoring less than $50 \%$ in quality were defined as "poor".

Level of evidence was assessed using the categories proposed in the Oxford Center for Evidence-Based medicine (CEMB) levels for diagnosis [2011] (5).

Disagreement were resolved by discussion between the reviewers.

\section{Results}

The systematic literature search provided 79 studies which met the inclusion and exclusion criteria.

Seventy-five papers were case-control studies and 4 case-series studies.

Fifty-one (64\%) papers were focused on malignant tumors, $14(17.5 \%)$ papers on neurologic diseases and 14 $(18.5 \%)$ on inflammatory/cardiovascular/metabolic diseases (Table 2, Table 3, Table 4).

Molecules investigated were DNA, RNA, proteins, metabolites, microbiota and combination of these.

Results of search strategy are summarized in Fig. 1.

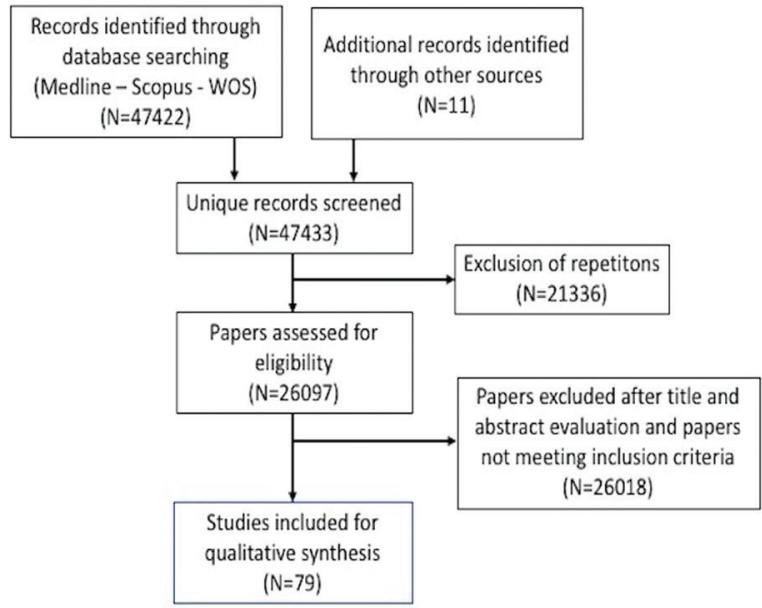

Fig. 1: Search strategy. 
Table 2: Papers on salivary biomarkers for diagnosis of malignant tumors.

\begin{tabular}{|c|c|}
\hline Authors and year & Title \\
\hline Streckfus C et al. (2000) (28) & $\begin{array}{l}\text { A Preliminary Study of CA15-3, c-erbB-2, Epidermal Growth Factor Receptor, Ca- } \\
\text { thepsin-D, and p53 in Saliva Among Women with Breast Carcinoma }\end{array}$ \\
\hline Turan T et al. (2005) (29) & $\begin{array}{l}\text { Free and Total Prostate-Specific Antigen Levels in Saliva and the Comparison with } \\
\text { Serum Levels in Men }\end{array}$ \\
\hline Streckfus C et al (30) & $\begin{array}{l}\text { The use of soluble, salivary c-erbB-2 for the detection and post-operative follow-up } \\
\text { of breast cancer in women: the results of a five-year translational research study }\end{array}$ \\
\hline Streckfus C et al. (2006) (28) & $\begin{array}{l}\text { The use of surface-enhanced laser desorption/ionization time-of-flight mass spec- } \\
\text { trometry to detect putative breast cancer markers in saliva: a feasibility study }\end{array}$ \\
\hline Brooks MN et al. (2008) (31) & Salivary protein factors are elevated in breast cancer patients \\
\hline Wu ZZ et al (2009) (25) & Diagnostic model of saliva protein finger print analysis of patients with gastric cancer \\
\hline Agha-Hosseini F et al. (2009) (32) & Correlation of serum and salivary CA15-3 levels in patients with breast cancer \\
\hline Sugimoto M et al. (2009) (33) & $\begin{array}{l}\text { Capillary electrophoresis mass spectrometry-based saliva metabolomics identified } \\
\text { oral, breast and pancreatic cancer-specific profiles }\end{array}$ \\
\hline Zhang L et al. (2009) (12) & Salivary transcriptomic biomarkers for detection of resectable pancreatic cancer \\
\hline Xiao H et al. (2012) (54) & $\begin{array}{l}\text { Proteomic analysis of human saliva from lung cancer patients using two-dimension- } \\
\text { al difference gel electrophoresis and mass spectrometry }\end{array}$ \\
\hline Lee YH et al. (2012) (55) & $\begin{array}{l}\text { Salivary transcriptomic biomarkers for detection of ovarian cancer: for serous papil- } \\
\text { lary adenocarcinoma }\end{array}$ \\
\hline Zhang L et al. (2012) (56) & $\begin{array}{l}\text { Discovery and preclinical validation of salivary transcriptomic and proteomic bio- } \\
\text { markers for the non-invasive detection of breast cancer }\end{array}$ \\
\hline Li X et al. (2012) (57) & $\begin{array}{l}\text { Spectral analysis of human saliva for detection of lung cancer using surface en- } \\
\text { hanced Raman spectroscopy }\end{array}$ \\
\hline Zhang L et al. (2012) (8) & $\begin{array}{l}\text { Development of transcriptomic biomarker signature in human saliva to detect lung } \\
\text { cancer }\end{array}$ \\
\hline De Abreu Pereira D et al. (2012) (58) & Measurement of HER2 in saliva of women in risk of breast cancer \\
\hline Holten-Andersen L et al. (2012) (14) & Saliva and plasma TIMP-1 in patients with colorectal cancer: a prospective study \\
\hline Laidi F et al. (2014) (7) & $\begin{array}{l}\text { Salivary expression of soluble HER } 2 \text { in breast cancer patients with positive and } \\
\text { negative HER } 2 \text { status }\end{array}$ \\
\hline Wei F et al. (2014) (10) & Noninvasive saliva-based EGFR gene mutation detection in patients with lung cancer \\
\hline Chen D et al. (2014) (59) & Saliva as a sampling source for the detection of leukemic fusion transcripts \\
\hline Xie Z et al. (2014) (13) & $\begin{array}{l}\text { Salivary microRNAs show potential as a noninvasive biomarker for detecting re- } \\
\text { sectable pancreatic cancer }\end{array}$ \\
\hline Feng S et al. (2015) (6) & $\begin{array}{l}\text { Surface-enhanced Raman spectroscopy of saliva proteins for the noninvasive dif- } \\
\text { ferentiation of benign and malignant breast tumors }\end{array}$ \\
\hline Cheng F et al. (2015) (60) & $\begin{array}{l}\text { Investigation of salivary free amino acid profile for early diagnosis of breast cancer } \\
\text { with ultra performance liquid chromatography-mass spectrometry }\end{array}$ \\
\hline Humeau M et al. (2015) (61) & Salivary MicroRNA in Pancreatic Cancer Patients \\
\hline Yan X et al. (2015) (62) & Discovery and validation of potential bacterial biomarkers for lung cancer \\
\hline Delmonico L et al. (2015) (63) & $\begin{array}{l}\text { CDKN2A (p14(ARF)/p16(INK4a)) and ATM promoter methylation in patients with } \\
\text { impalpable breast lesions }\end{array}$ \\
\hline Takayama T et al.(2015) (64) & $\begin{array}{l}\text { Diagnostic approach to breast cancer patients based on target metabolomics in saliva } \\
\text { by liquid chromatography with tandem mass spectrometry }\end{array}$ \\
\hline Torres PJ et al. (2015) (65) & Characterization of the salivary microbiome in patients with pancreatic cancer \\
\hline Wood $\mathrm{N}$ et al. (2015) (66) & $\begin{array}{l}\text { The Expression of Lung Resistance Protein in Saliva: A Novel Prognostic Indicator } \\
\text { Protein for Carcinoma of the Breast }\end{array}$ \\
\hline Tsutsui H et al. (2016) (67) & $\begin{array}{l}\text { High-throughput LC-MS/MS based simultaneous determination of polyamines in- } \\
\text { cluding N-acetylated forms in human saliva and the diagnostic approach to breast } \\
\text { cancer patients }\end{array}$ \\
\hline Xiao H et al.(2016) (49) & $\begin{array}{l}\text { Differential Proteomic Analysis of Human Saliva using Tandem Mass Tags Quanti- } \\
\text { fication for Gastric Cancer Detection }\end{array}$ \\
\hline $\mathrm{Pu} \mathrm{D}$ et al. (2016) (40) & $\begin{array}{l}\text { Evaluation of a novel saliva-based epidermal growth factor receptor mutation detec- } \\
\text { tion for lung cancer: A pilot study }\end{array}$ \\
\hline Xie z et al. (2016) (68) & Salivary HOTAIR and PVT1 as novel biomarkers for early pancreatic cancer \\
\hline Zhong L et al. (2016) (69) & $\begin{array}{l}\text { Untargeted saliva metabonomics study of breast cancer based on ultra performance liq- } \\
\text { uid chromatography coupled to mass spectrometry with HILIC and RPLC separations }\end{array}$ \\
\hline Machida $\mathrm{T} e t$ & $\begin{array}{l}\text { MiR-1246 and miR-4644 in salivary exosome as potential biomarkers for pancrea- } \\
\text { tobiliary tract cancer }\end{array}$ \\
\hline
\end{tabular}


Table 2 cont.: Papers on salivary biomarkers for diagnosis of malignant tumors.

\begin{tabular}{|c|c|}
\hline Liu HJ et al (2016) (71) & $\begin{array}{l}\text { Predicting novel salivary biomarkers for the detection of pancreatic cancer using } \\
\text { biological feature-based classification }\end{array}$ \\
\hline Shu J et al. (2017) (15) & Salivary glycopatterns as potential biomarkers for diagnosis of gastric cancer \\
\hline Bel'skaya et al. (2017) (72) & The activity of metabolic enzymes in the saliva of lung cancer patients \\
\hline Sun Y et al. (2017) (73) & $\begin{array}{l}\text { Systematic comparison of exosomal proteomes from human saliva and serum for the } \\
\text { detection of lung cancer }\end{array}$ \\
\hline Laidi F et al. (2017) (74) & $\begin{array}{l}\text { Usefulness of Salivary and Serum Auto-antibodies Against Tumor Biomarkers } \\
\text { HER2 and MUC1 in Breast Cancer Screening }\end{array}$ \\
\hline Hernández-Arteaga A et al. (2017) (75) & $\begin{array}{l}\text { Diagnosis of breast cancer by analysis of sialic acid concentrations in human saliva } \\
\text { by surface-enhanced Raman spectroscopy of silver nanoparticles }\end{array}$ \\
\hline Cavaco C et al. (201 & $\begin{array}{l}\text { Screening of salivary volatiles for putative breast cancer } \\
\text { discrimination: an exploratory study involving geographically distant populations }\end{array}$ \\
\hline Sun J et al. (2018) (16) & A screening method for gastric cancer by oral microbiome detection \\
\hline Zermeño-Nava JJ et al. (2018) (77) & $\begin{array}{l}\text { Determination of sialic acid in saliva by means of surface-enhanced Raman spec- } \\
\text { troscopy as a marker in adnexal mass patients: ovarian cancer vs benign cases }\end{array}$ \\
\hline Li F et al. (2018) (17) & $\begin{array}{l}\text { Discovery and Validation of Salivary Extracellular RNA Biomarkers for Noninva- } \\
\text { sive Detection of Gastric Cancer }\end{array}$ \\
\hline Yang J et al. (2018) (11) & $\begin{array}{l}\text { Dysbiosis of the Salivary Microbiome Is Associated With Non smoking Female } \\
\text { Lung Cancer and Correlated With Immunocytochemistry Markers }\end{array}$ \\
\hline Tajmul M et al. (2018) (78) & $\begin{array}{l}\text { Identification and validation of salivary proteomic signatures for non-invasive de- } \\
\text { tection of ovarian cancer }\end{array}$ \\
\hline Zhang J et al. (2018) (79) & $\begin{array}{l}\text { Identification of Abnormal Fucosylated-Glycans Recognized by LTL in Saliva of } \\
\text { HBV-Induced Chronic Hepatitis, Cirrhosis, and Hepatocellular Carcinoma }\end{array}$ \\
\hline Shu J et al. (2018) (48) & $\begin{array}{l}\text { Identification of } \mathrm{N} \text { - and O-linked glycans recognized by AAL in saliva of patients } \\
\text { with atrophic gastritis and gastric cancer }\end{array}$ \\
\hline Xie Z et al. (2018) (80) & $\begin{array}{l}\text { Lnc-PCDH9-13:1 Is a Hypersensitive and Specific Biomarker for Early Hepatocel- } \\
\text { lular Carcinoma }\end{array}$ \\
\hline Chen Y et al. (2018) (47) & $\begin{array}{l}\text { Salivary Analysis Based on Surface Enhanced Raman Scattering Sensors Distin- } \\
\text { guishes Early and Advanced Gastric Cancer Patients from Healthy Persons }\end{array}$ \\
\hline Koizumi T et al. (2018) (9) & Salivary cytokine panel indicative of non-small cell lung cancer \\
\hline
\end{tabular}

Table 3: Papers on salivary biomarkers for diagnosis of neurologic diseases.

\begin{tabular}{|c|l|}
\hline Authors and year & \multicolumn{1}{c|}{ Title } \\
\hline Devic I et al. (2011) (81) & Salivary $\alpha$-synuclein and DJ-1: potential biomarkers for Parkinson's disease \\
\hline Tsuruoka M et al. (2013) (82) & $\begin{array}{l}\text { Capillary electrophoresis-mass spectrometry-based metabolome analysis of serum and sa- } \\
\text { liva from neurodegenerative dementia patients }\end{array}$ \\
\hline Al-Nimer MS et al (2014) (83) & $\begin{array}{l}\text { Saliva } \alpha \text {-Synuclein and A High Extinction Coefficient Protein: A Novel Approach in As- } \\
\text { sessment Biomarkers of Parkinson's Disease }\end{array}$ \\
\hline Masters JM et al. (2015) (18) & $\begin{array}{l}\text { Elevated salivary protein in Parkinson's disease and salivary DJ-1 as a potential marker of } \\
\text { disease severity }\end{array}$ \\
\hline Liang Q et al. (2015) (84) & Metabolomics-based screening of salivary biomarkers for early diagnosis of Alzheimer's disease \\
\hline Liang Q et al. (2016) (85) & $\begin{array}{l}\text { High-throughput metabolomics analysis discovers salivary biomarkers for predicting mild } \\
\text { cognitive impairment and Alzheimer's disease }\end{array}$ \\
\hline Yilmaz A et al. (2017) (86) & $\begin{array}{l}\text { Diagnostic Biomarkers of Alzheimer's Disease as Identified in Saliva using 1H NMR-Based } \\
\text { Metabolomics. }\end{array}$ \\
\hline Ashton NJ et al. (2018) (87) & No association of salivary total tau concentration with Alzheimer's disease \\
\hline Cao Z et al. (2018) (88) & a-Synuclein in salivary extracellular vesicles as a potential biomarker of Parkinson's disease \\
\hline Ahmadi-Motamayel F et al. & $\begin{array}{l}\text { Evaluation of salivary acetylcholinesterase and } \\
\text { pseudocholinesterase in patients with Alzheimer's disease: A case-control study }\end{array}$ \\
\hline Song W et al. (2018) (89) & $\begin{array}{l}\text { Evaluation of Salivary Heme Oxygenase-1 as a Potential Biomarker of Early Parkinson's } \\
\text { Disease }\end{array}$ \\
\hline Manconia B et al. (2018) (90) & Top-down proteomic profiling of human saliva in multiple sclerosis patients \\
\hline Vivacqua G et al. (2019) (37) & $\begin{array}{l}\text { Salivary alpha-synuclein in the diagnosis of Parkinson's disease and Progressive Supra- } \\
\text { nuclear Palsy }\end{array}$ \\
\hline Marksteiner J et al. (2019) (38) & $\begin{array}{l}\text { Acyl-Alkyl Phosphatidlycholines are Decreased in Saliva of Patients with Alzheimer's Dis- } \\
\text { ease as Identified by Targeted Metabolomics }\end{array}$ \\
\hline
\end{tabular}


Table 4: Papers on salivary biomarkers for diagnosis of inflammatory/cardiovascular/metabolic diseases.

\begin{tabular}{|c|l|}
\hline Authors and year & \multicolumn{1}{c|}{ Title } \\
\hline Rao PV et al. (2008) (35) & Proteomic identification of salivary biomarkers of type-2 diabetes \\
\hline Floriano PN. et al (2009) (23) & $\begin{array}{l}\text { Use of Saliva-Based Nano-Biochip Tests for Acute Myocardial Infarction at the Point of } \\
\text { Care: A Feasibility Study }\end{array}$ \\
\hline Giusti L. et al. (2010) (26) & Is GRP78/BiP a potential salivary biomarker in patients with rheumatoid arthritis? \\
\hline Buduneli E et al. (2011) (91) & Acute myocardial infarction is reflected in salivary matrix metalloproteinase-8 activation level. \\
\hline Silva DG et al. (2011) (92) & $\begin{array}{l}\text { Higher levels of salivary MUC5B and MUC7 in individuals with gastric diseases who } \\
\text { harbor Helicobacter pylori }\end{array}$ \\
\hline Mirzaii-Dizgah I et al. (2011) (21) & Unstimulated whole saliva creatine phosphokinase in acute myocardial infarction \\
\hline Mirzaii-Dizgah I et al. (2011) (24) & Serum and saliva levels of cathepsin L in patients with acute coronary syndrome. \\
\hline Mirzaii-Dizgah I et al. (2012) (22) & $\begin{array}{l}\text { Saliva-based creatine kinase MB measurement as a potential point-of-care testing for } \\
\text { detection of myocardial infarction. }\end{array}$ \\
\hline Mirzaii-Dizgah I et al. (2013) (20) & Salivaryhigh-sensitivity cardiactroponin Tlevels in patients with acutemyocardialinfarction \\
\hline Mirzaii-Dizgah I et al. (2013) (93) & Salivary troponin I as an indicator of myocardial infarction \\
\hline Adornetto G et al. (2015) (94) & An electrochemical immunoassay for the screening of celiac disease in saliva samples \\
\hline Cao G et al. (2015) (95) & $\begin{array}{l}\text { A potential method for non-invasive acute myocardial infarction detection based on saliva } \\
\text { Raman spectroscopy and multivariate analysis. }\end{array}$ \\
\hline Giusti L et al. (2015) (96) & $\begin{array}{l}\text { Salivary psoriasin (S100A7) correlates with diffusion capacity of carbon monoxide in a } \\
\text { large cohort of systemic sclerosis patients }\end{array}$ \\
\hline Lu C et al. (2017) (97) & $\begin{array}{l}\text { Detection of AMA-M2 in human saliva: Potentials in diagnosis and monitoring of pri- } \\
\text { mary biliary cholangitis }\end{array}$ \\
\hline
\end{tabular}

- Critical appraisal of the selected papers

Following the NIH guidelines modified according to the methodology of the present systematic review, $19(24 \%)$ studies were scored as "good", 45 (57\%) were "fair" and $15(19 \%)$ had "poor" quality.

The most frequently encountered risk of bias (ROBs) were the absence of concurrent controls (71 papers), the lack of sample size justification (70 papers), the lack of randomization (70 papers) and absence of report of blinding exposure assessors (68 papers).

- Level of evidence

Application of the Oxford CEMB guidelines highlighted that all of the selected papers have a low level of evidence ( 4 on 5 , the fifth level being the lowest), because of their case control or case series design.

- Malignant tumors

Breast cancer was the most investigated disease (18 papers), followed by lung cancer (10 papers), gastric cancer (7 papers) and pancreatic cancer (6 papers). Other cancers included leukemia, prostate, ovarian, colorectal, pancreatobiliary and hepatocellular cancer.

Molecules most frequently investigated were proteins and RNA.

Twelve studies (23.5\%) were scored as "good" and 11 of these reported statistically significant associations between molecules searched and pathology (6-17).

The twelve studies are summarized in Table 5.

- Neurologic diseases

Fourteen papers were focused on neurologic diseases. Among these, 7 papers investigated Alzheimer's disease, 6 investigatedParkinson'sdiseasesandonemultiplesclerosis.
Two papers were scored as "good". One study searched DJ-1 proteins in Parkinson's patients (not statistically significant association) (18). The other one analyzed salivary metabolites in patient with Alzheimer's disease and found a statistically significant association between disease and biomarkers (19).

Details on such papers are reported in Table 6 .

- Inflammatory/cardiovascular/metabolic diseases

Fourteen papers were included in this category, the pathologies investigated being diabetes, myocardial infarction, rheumatoid arthritis, gastric diseases, celiac disease and coronary syndrome.

Myocardial infarction was the most frequently studied disease (7 papers, $50 \%$ ).

"Good" quality articles were 5, four focused on myocardial infarction and one on coronary syndrome. All studies searched for proteins and 5 of these reported significant results. (20-24)

Papers are summarized in Table 7.

- Biochemical technologies

It goes beyond the aim of the present systematic review to critically discuss the biochemical mehods utilized in the studies included.

Almost all the studies on genetic molecules used Polymerase Chain Reaction (PCR) technique.

The studies on proteins used mainly Enzyme-Linked Immunosorbent Assays (ELISA) or Mass Spectrometry (MS). Few studies used Surface Enhanced Raman Scattering (SERS) and Luminex.

For searching metabolites, the preferred technique was MS. 
Table 5: Good quality studies on salivary biomarkers for diagnosis of malignant tumors.

\begin{tabular}{|c|c|c|c|c|}
\hline $\begin{array}{c}\text { AUTHORS AND } \\
\text { YEAR }\end{array}$ & PATHOLOGY & \begin{tabular}{|l|} 
CATEGORY OF \\
MOLECULE
\end{tabular} & BIOMARKERS & ASSOCIATION \\
\hline \begin{tabular}{|} 
Xie Z. et al. (2014) \\
(13)
\end{tabular} & Pancreatic cancer & RNA & miR-3679-5p, miR-940 & Significant $(p<0.008)$ \\
\hline $\begin{array}{l}\text { Zhang L. et al. } \\
\text { (2009) (12) }\end{array}$ & Pancreatic cancer & RNA & $\begin{array}{l}\text { KRAS, MBD3L2, ACRV1, } \\
\text { DPM1* }\end{array}$ & Significant $(p<0.0001)$ \\
\hline $\begin{array}{l}\text { Wei F. et al. (2014) } \\
(10)\end{array}$ & Lung cancer & DNA & EGFR** & Significant $(p<0.0001)$ \\
\hline $\begin{array}{l}\text { Zhang L. et al } \\
\text { (2012) (8) }\end{array}$ & Lung cancer & RNA & CCNI, EGFR, FRS2, GREB1*** & Significant $(p<0.05)$ \\
\hline $\begin{array}{l}\text { Yang J. Et al. } \\
(2018)(11)\end{array}$ & Lung cancer & microbiome & $\begin{array}{l}\text { sphingomonas, blastomonas, aci- } \\
\text { netobacter, streptococcus }\end{array}$ & $\begin{array}{c}\text { Significant }(p<0.05,0.0001, \\
0.01)\end{array}$ \\
\hline $\begin{array}{l}\text { Koizumi T. et al. } \\
\text { (2018) (9) }\end{array}$ & Lung cancer & proteins $/ \mathrm{aa}^{\circ \circ}$ & $\begin{array}{l}\text { Cytokine (IL1RN, IL1B, IL6, IL7, } \\
\text { IL8, IL10, CCL1, TNF, CXCL10, } \\
\text { CC3, CC4, PDGF BB)**** }\end{array}$ & Significant $(p<0.05)$ \\
\hline $\begin{array}{l}\text { Feng S. et al. } \\
(2015)(6)\end{array}$ & Breast cancer & proteins/aa & $\begin{array}{l}\text { phenylalanine, triptophane, tyro- } \\
\text { sine, proline, collagene }\end{array}$ & Significant $(p<0.05)$ \\
\hline $\begin{array}{l}\text { Laidi F. et al. } \\
\quad(2014)(7)\end{array}$ & Breast cancer & proteins/aa & HER2***** & Not Significant $(p>0.05)$ \\
\hline $\begin{array}{l}\text { Holten-Andersen } \\
\text { et al. (2012) (14) }\end{array}$ & Colorectal cancer & proteins/aa & TIMP-1****** & Not significant $(p=0.52)$ \\
\hline $\begin{array}{l}\text { Sun J. et al. (2018) } \\
\text { (16) }\end{array}$ & Gastric cancer & microbiome & $\begin{array}{l}\text { prevotella, leptotrichia, rothia, } \\
\text { aggregatibacter, campylobacter, } \\
\text { megasphaera, granulicatella }\end{array}$ & $\begin{array}{c}\text { Significant }(p<0.04, p<0.01, \\
p<0.005)\end{array}$ \\
\hline $\begin{array}{l}\text { Li F. et al. } \\
(2018)(17)\end{array}$ & Gastric cancer & RNA & $\begin{array}{l}\text { SPINK7, PPL, SEMA4B, miR- } \\
140-5 \mathrm{p}, \mathrm{miR} 301 \mathrm{a}\end{array}$ & Significant $(p<0.05)$ \\
\hline $\begin{array}{l}\text { Shu J. et al. (2017) } \\
\text { (15) }\end{array}$ & Gastric cancer & proteins/aa & Glycoproteins & Significant $(p<0.01)$ \\
\hline
\end{tabular}

* KRAS: Kirsten RAt Sarcoma virus; MBD3L2: Methyl-CpG Binding Domain Protein 3 Like 2; ACRV1: acrosomal vesicle protein 1; DPM1: Dolichyl-Phosphate Mannosyltransferase Subunit 1; **EGFR: epidermal growth factor receptor; ***CCNI: cyclin-1 gene; FRS2: Fibroblast growth factor receptor substrate 2 gene; GREB1: Growth regulation by estrogen in breast cancer 1 gene; **** IL1RN: interleukin receptor antagonist, CCL11: C-C motif chemokine ligand 11, TNF: tumor necrosis factor, CXCL10: C-X-C motif chemokine ligand 10, CC3: C-C motif chemokine ligand 3, CC4: C-C motif chemokine ligand 4, PDGF BB: platelet-derived growth factor-BB; *****HER2: human epidermal growth factor receptor $2 ; * * * * *$ TIMP-1: tissue inhibitor of metalloproteinases $1 ;{ }^{\circ}$ aa: aminoacids.

Table 6: Good quality studies on salivary biomarkers for diagnosis of neurologic disease.

\begin{tabular}{|c|c|c|c|c|}
\hline AUTHORS AND YEAR & PATHOLOGY & $\begin{array}{c}\text { CATEGORY OF } \\
\text { MOLECULE }\end{array}$ & BIOMARKERS & ASSOCIATION \\
\hline $\begin{array}{c}\text { Masters J.M. } \text { et al. } \text { (2015) } \\
(18)\end{array}$ & Parkinson's disease & proteins/aa** & DJ-1* & Not significant $(p=0.6)$ \\
\hline $\begin{array}{c}\text { Ahmadi-Motamayel F. et } \\
\text { al. (2018) (19) }\end{array}$ & Alzheimer's disease & metabolites & $\begin{array}{c}\text { acetylcholinesterase, } \\
\text { pseudocholinesterase }\end{array}$ & Significant $(p<0.002)$ \\
\hline
\end{tabular}

*DJ-1 : Proteine deglycase DJ1

** aa: aminoacids

Table 7: Good quality studies on salivary biomarkers for diagnosis of inflammatory/cardiovascular/metabolic diseases.

\begin{tabular}{|c|c|c|c|c|}
\hline $\begin{array}{c}\text { AUTHORS AND } \\
\text { YEAR }\end{array}$ & PATHOLOGY & $\begin{array}{c}\text { CATEGORY OF } \\
\text { MOLECULE }\end{array}$ & BIOMARKERS & ASSOCIATION \\
\hline $\begin{array}{c}\text { Floriano P. } \text { et } \mathrm{Al} \\
(2009)(23)\end{array}$ & Myocardial infarction & proteins/aa** & C-RP, MYO, MPO* & Significant $(p>0.0001)$ \\
\hline $\begin{array}{c}\text { Mirzaii-Dizgah } \text { et } \mathrm{Al} \\
(2011)(21)\end{array}$ & Myocardial infarction & proteins/aa & Creatine phosphokinase & Significant $(p<0.01)$ \\
\hline $\begin{array}{c}\text { Mirzaii-Dizgah } \text { et } \mathrm{Al} \text { (CKP) } \\
(2012)(22)\end{array}$ & Myocardial infarction & proteins/aa & Creatin kinase MB (CK-MB) & Significant $(p<0.001)$ \\
\hline $\begin{array}{c}\text { Mirzaii-Dizgah } \text { et } \mathrm{Al} \\
(2012)(20)\end{array}$ & Myocardial infarction & proteins/aa & Cardiac troponin T & Significant $(p<0.02)$ \\
\hline $\begin{array}{c}\text { Mirzaii-Dizgah } \text { et } \mathrm{Al} \\
(2011)(24)\end{array}$ & Coronary syndrome & proteins/aa & Cathepsin-L & Not significant $(p=0.02)$ \\
\hline
\end{tabular}

* C-RP: c-reactive protein; MYO: myoglobine; MPO: myeloperoxidase; ** aa: aminoacids 


\section{Discussion}

The present systematic review has highlighted an increased scientific interest toward the use of salivary biomarkers for diagnosis of systemic diseases and malignant tumors. Even limiting the field of interest only to diagnosis and applying strict inclusion and exclusion criteria, the number of papers appears considerable. It is worthy to mention here that among the 79 papers included, only 12 studies were conducted before 2010, the rest being published after such year (12,23,25-34). The most investigated salivary molecules are proteins (43 studies), followed by metabolites (15 studies) and RNA (12 studies). Surprisingly, the less studied salivary biomarkers are those based on DNA (3 studies) and microbiota (2 studies) analysis, despite their popularity for other aims (e.g ancestry investigations, biocompatibility for transplant, forensic analysis, dietary implications) $(35,36)$.

In recent years, there has been a shifting of interest in the typology of molecules investigated. In fact, even if proteins remained predominant, there has been an increase of researches dealing with salivary metabolites (16 papers in 2018 and 2 papers in the first half of 2019) $(37,38)$.

Most of the studies included in the present systematic review (69 out of $79-87 \%$ ) showed statistically significant correlations between one or more biomarkers and specific pathologies. Such results would, in general, indicate the possibility to use peculiar salivary molecules for early diagnosis of diseases. However, critical appraisal and quality assessment highlighted that most of these studies did not satisfy a relevant percentage the items suggested by the NIH formats. As a matter of facts, only 19 studies received a score indicating "good" quality. Also, the level of evidence of all of the examined studies appears quite low.

One of the most frequently encountered ROBs was the lack of sample size justification. Calculation of a sample size is a fundamental step for creating reliable researches. Groups of patients too small have little chance of meeting the study objectives (39). Therefore, particularly for studies on salivary biomarkers it seems very important to report the justification of the population size. On the other hand, it should be taken into account that several studies included in the present review were pilot studies $(27,40)$. For such a typology of research, it is usually difficult to provide a statistical reliable sample size justification, on the basis of the absence of background data in the literature (41). It is opinion of the Authors of the present systematic review that, the described ROB may largely depend on the fact that many of the studies took into consideration many variables at the same time (e.g. panel or combinations of very different biomolecules, biomarkers evaluated for the first time in saliva, patients with diseases at different stages), thus making more or less impossible to calculate a reliable sample size.

The second most frequently encountered ROBs involved the absence of blinding of exposure assessor. Blinding is important to remove bias that could influence the way the data is processed. The two major biases that can be controlled using blinding are the performance bias (differences that occur due to knowledge of intervention allocation, in either the researcher or the participant that cause differences in the care received) and the ascertainment bias (when data for a study or analysis is collected, surveyed, screened, or recorded, such that some members of the intended population are less likely to be included than others) (42). In the studies evaluated, the ROBs "absence of blindness" was induced by the fact that it was not specified if the biochemical analyst was or was not unaware of the provenance of the specimen (e.g. case or control group).

The most investigated disease in the present review was breast cancer (18 out of 79 studies), the most common malignant tumor among women $(25 \%$ off all females tumors), with approximately 1.7 million new cases diagnosed every year (43). Fourteen studies (78\%) reported statistically significant association between the presence of breast tumor and finding of one or more markers in patients saliva. Molecules such C-erbB2, CA 15-3, Cathepsin D, sialic acid and P53, EGF, VEGF and the CEA, seem to be promising salivary markers possibly very useful either for diagnosis of breast carcinoma and for follow-up of patients after treatment. According to the quality assessment tool adopted here, only one study dealing with breast cancer and salivary biomarkers obtained a "good" quality score, its results being apparently very robust (6). However, such a study investigated a panel of proteins, detected trough the SERS technology, which are not yet completely characterized and identified (6). Therefore, the utility of these proteins is currently somewhat questionable and their role should be confirmed in further studies.

The second most studied malignant tumor, according to the present systematic review is lung carcinoma (10 studies). Lung cancer is the most common cancer in humans (11.6\% of all malignant tumours) and the leading cause of death for malignancy (18.4\%) (44). All of the researches on patients with lung carcinomas provided statistically significant results to the association between salivary molecules and the pulmonary malignancy. Specifically, molecules identified included a mutation of the EGFR gene, 5 mRNA (CCNI, EGFR, FGF 19, FRS 2, GREB1), several bacteria (e.g. Sphingomonas, Blastomonas, Acinetobacter, Streptococcus) and proteins such as the calprotectin, alkaline phosphatase, cytokines, AZGP1 and haptoglobine (HP). All the reported molecules showed a good statistical association with diagnosis of lung carcinomas at different stages of 
developement. The "good" quality studies on salivary biomarkers and lung cancer are those demonstrating an association with EGFR, the 5 mRNA, microbiota and cytokines (8-11). According to the results of the present review they can be considered already reliable markers. Data on association between salivary biomarkers and diagnosis of malignant tumors are available also for gastric and pancreatic cancer. Gastric cancer affects approximately one million individuals per year worldwide, having a mortality rate of approximately (1.033.701 new cases in 2018 and 782.685 death in 2018 , in the world) (44). It is often detected late because up to $80 \%$ of patients are asymptomatic during the early phases of disease (45). Similarly, pancreatic carcinoma is insidious, very aggressive and in most cases diagnosed at a very late stage, being associated to a very poor prognosis (46).

With regard to gastric cancer 7 studies were included in the present review (15-17,25,47-49). All of these reported statistically significant results. The "good" quality studies were three and they were focused on salivary bacteria (Prevotella, Leptotrichia, Rothia, Aggregatibacter, Campylobacter, Megasphaera, Granulicatella), RNA (SPINK7, PPL, SEMA4B, miR140-5p, miR301a) and some lectins.

All of the studies on pancreatic cancer demonstrated a significant association between the salivary molecules and the disease. Two of these were also scored as "good" after quality assessment. Molecules reported in such analysis were derived from transcriptomics (4mRNA (KRAS, MBD3L2, ACRV1, DPM1), and 2 miRNA (miR-3679-5p and miR-940)).

It is worthy to mention here that both for gastric and pancreatic cancer, the possibility of early diagnosis through salivary diagnostics, not based on the subjective radiographical images interpretation, could potentially contribute to prevent most of the deaths related to such cancers (3).

Particularly in the field of oncology, an easy and noninvasive method based on salivary biomarkers, may hypothetically constantly monitor and screen saliva, thus detecting very recurrences very (50).

Studies on neurological disorders are focused on Parkinson's and Alzheimer's diseases. It is interesting to highlight that the use of salivary biomarkers in patients with neurological pathologies has gained a great interest in the last couple of years ( 8 out 14 articles published in 2017-18). Such an increasing of interest might be explained taking into consideration that the diagnosis of these diseases are essentially clinical. The identification of objective features (including biomolecules within body fluid) seems therefore of paramount importance for diagnosis, monitoring of disease progression and management as well as the development of novel therapeutic interventions (51).
Among studies on inflammatory, cardiovascular and metabolic diseases those reporting significant results are focused on myocardial infarction and rheumatoid arthritis $(20-24,26)$.

Research on myocardial infarction searched C-reactive protein, myoglobin, myeloperoxidase, creatine phosphokinase, creatin kinase MB, cardiac troponin $\mathrm{T}$ and cathepsin-L, all reporting statistically significant result. In one of these studies the use a saliva-based nanochip was proposed (23). Such a new technology, based on nanotechnologies and innovative materials, is apparently very promising, deserving further researches.

Rheumatoid arthritis is sometime difficult to diagnose, especially in early stages, because of the variability of the symptoms and the absence of specific markers (52). Early diagnosis of the disease usually improves the success of treatment and could possibly reduce the quantity of drugs administered. In the study on included in the present review, Authors identified particularly one salivary protein (GRP78/BiP) which was significantly associated to the disease $(p<0.001,83.3 \%$ sensitivity and $95 \%$ specificity) (26).

A limit of the present systematic review is the lack of a quantitative analysis. The heterogeneity of diseases evaluated, their stage at diagnosis, the extremely wide range of molecules investigated as well as the differences in procedures for saliva collection, handling, storing and processing, makes it impossible to draw reliable pooled results or to perform a meta-analysis. On the other hand, the results of the present qualitative analysis can provide useful information in the field of salivary diagnostics. Particularly, the findings reported here can be the background for further studies which possibly might take into account the ROBs highlighted in the qualitative analysis of papers. Future studies might be useful to confirm and improve the potentiality of salivary analysis techniques (in terms of sensitivity and specificity) as well as to develop new, smaller, patientfriendly devices possibly with affordable costs.

Diffusion and ready availability of a panel of sensors for detecting salivary biomarkers associated to systemic diseases could have a strong impact on public healthcare and economy. The use of saliva for analysis might replace the use of blood, with a possible economic impact based on the easier and non-invasive method for collection (50). Such a perspective, may well lead to a higher commercial availability of screening assays (53) and possibly bring to the development of analytic tools directly administered in the dental or general physician office.

The use of salivary biomarkers for diagnosis of systemic diseases ("salivary diagnostics") is gaining increasing interest.

The present systematic review confirms the existence of some "good" quality evidence to support the role 
of peculiar salivary biomarkers for diagnosis of systemic diseases (e.g. lung cancer and EGFR). However, it seems necessary to encourage further researches for improving the sensitivity and specificity of salivary diagnostics analysis.

The perspective of realizing a reliable "lab-on-a-chip" for diagnosis and follow-up of systemic diseases and/or malignant tumors through saliva evaluation seems an attainable target of modern medicine.

\section{References}

1. Aro K, Wei F, Wong DT, Tu M. Saliva Liquid Biopsy for Point-ofCare Applications. Front Public Health. 2017;5:77.

2. Yager P, Domingo GJ, Gerdes J. Point-of-Care Diagnostics for Global Health. Annu Rev Biomed Eng. 2008;10:107-44.

3. Kaczor-Urbanowicz KE, MartinCarreras-Presas C, Aro K, Tu M, Garcia-Godoy F, Wong DT. Saliva diagnostics - Current views and directions. Exp Biol Med. 2017;242:459-72.

4. https://www.nhlbi.nih.gov/health-topics/study-quality-assessmenttools

5. Phillips B, et al. Oxford Centre for Evidence-based Medicine-Levels of Evidence. 2009. Retrieved from http://www.cebm.net/oxfordcentre-evidence-based-medicine-levels-evidence-march-2009/

6. Feng S, Huang S, Lin D, Chen G, Xu Y, Li Y, et al. Surface-enhanced Raman spectroscopy of saliva proteins for the noninvasive differentiation of benign and malignant breast tumors. Int J Nanomedicine. 2015;10:537-47.

7. Laidi F, Bouziane A, Zaoui F. Salivary expression of soluble HER2 in breast cancer patients with positive and negative HER2 status. Onco Targets Ther. 2014;7:1285-89.

8. Zhang L, Xiao H, Zhou H, Santiago S, Lee JM, Garon EB, et al. Development of transcriptomic biomarker signature in human saliva to detect lung cancer. Cell Mol Life Sci. 2012;69:3341-50.

9. Koizumi T, Shetty V, Yamaguchi M. Salivary cytokine panel indicative of non-small cell lung cancer. J Int Med Res. 2018;46:3570-82.

10. Wei F, Lin CC, Joon A et al. Noninvasive saliva-based EGFR gene mutation detection in patients with lung cancer. Am J Respir Crit Care Med. 2014;190:1117-26.

11. Yang J, Mu X, Wang Y, Zhu D, Zhang J, Liang C, Chen B et al. Dysbiosis of the Salivary Microbiome Is Associated With Nonsmoking Female Lung Cancer and Correlated With Immunocytochemistry Markers. Front Oncol. 2018;8:520.

12. Zhang L, Farrell JJ, Zhou H, Elashoff D, Akin D, Park NH, et al. Salivary Transcriptomic Biomarkers for Detection of Resectable Pancreatic Cancer. Gastroenterology. 2010;138:949-57.

13. Xie Z, Yin X, Gong B, et al. Salivary microRNAs show potential as a noninvasive biomarker for detecting resectable pancreatic cancer. Cancer Prev Res. 2015;8:165-3.

14. Holten-Andersen L, Christensen IJ, Jensen SB, Reibel J, Laurberg S, Nauntofte B, et al. Saliva and plasma TIMP-1 in patients with colorectal cancer: a prospective study. Scand J Gastroenterol. 2012;47:1234-41.

15. Shu J, Yu H, Li X, Zhang D, Liu X, Du H. Salivary glycopatterns as potential biomarkers for diagnosis of gastric cancer. Oncotarget. 2017;8:35718-27.

16. Sun JH, Li XL, Yin J, Li YH, Hou BX, Zhang Z. A screening method for gastric cancer by oral microbiome detection. Oncol Rep. 2018;39:2217-24.

17. Li F, Yoshizawa JM, Kim KM, Kanjanapangka J, Grogan TR, Wang X, et al. Discovery and Validation of Salivary Extracellular RNA Biomarkers for Noninvasive Detection of Gastric Cancer. Clin Chem. 2018;64:1513-21.

18. Masters JM, Noyce AJ, Warner TT, Giovannoni G, Proctor GB. Elevated salivary protein in Parkinson's disease and salivary DJ-1 as a potential marker of disease severity. Parkinsonism relat disord. 2015;21:1251-5.
19. Ahmadi-Motamayel F, Goodarzi MT, Tarazi S, Vahabian M. Evaluation of salivary acetylcholinesterase and pseudocholinesterase in patients with Alzheimer's disease: A case-control study. Spec Care Dentist. 2019;39:39-44.

20. Mirzaii-Dizgah I, Riahi E. Salivary high-sensitivity cardiac troponin $\mathrm{T}$ levels in patients with acute myocardial infarction. Oral Dis. 2013;19:180-4.

21. Mirzaii-Dizgah I, Jafari-Sabet M. Unstimulated whole saliva creatine phosphokinase in acute myocardial infarction. Oral Dis. 2011;17:597-600.

22. Mirzaii-Dizgah I, Hejazi SF, Riahi E, Salehi MM. Saliva-based creatine kinase MB measurement as a potential point-of-care testing for detection of myocardial infarction. Clin Oral Investig. 2012;16:775-9.

23. Floriano PN, Christodoulides N, Miller CS, Ebersole JL, Spertus $\mathrm{J}$, Rose BG, et al. Use of Saliva-Based Nano-Biochip Tests for Acute Myocardial Infarction at the Point of Care: A Feasibility Study. Clin chem. 2009;55:1530-8.

24. Mirzaii-Dizgah I, Riahi E. Serum and Saliva Levels of Cathepsin L in Patients with Acute Coronary Syndrome. J Contemp Dent Pract. 2011;12:114-9.

25. Wu ZZ, Wang JG, Zhang XL. Diagnostic model of saliva protein finger print analysis of patients with gastric cancer. World journal of gastroenterology. 2009;15:865-70.

26. Giusti L, Baldini C, Ciregia F, Giannaccini G, Giacomelli C, De Feo $\mathrm{F}$, et al. Is GRP78/BiP a potential salivary biomarker in patients with rheumatoid arthritis? Proteomics Clinical Appl. 2010;4:315-24. 27. Streckfus C, Bigler L, Tucci M, Thigpen JT. A preliminary study of CA15-3, c-erbB-2, epidermal growth factor receptor, cathepsin$\mathrm{D}$, and $\mathrm{p} 53$ in saliva among women with breast carcinoma. Cancer Invest. 2000;18:101-9.

28. Streckfus C, Bigler L. The use of soluble, salivary c-erbB-2 for the detection and post-operative follow-up of breast cancer in women: the results of a five-year translational research study. Adv Dent Res. 2005;18:17-24.

29. Turan T, Demir S, Aybek H, Atahan O, Tuncay OL, Aybek Z, et al. Free and Total Prostate-Specific Antigen Levels in Saliva and the Comparison with Serum Levels in Men. Eur Urol. 2000;38:550-4.

30. Streckfus CF, Bigler LR, Zwick M. The use of surface-enhanced laser desorption/ionization time-of-flight mass spectrometry to detect putative breast cancer markers in saliva: A feasibility study. J Oral Pathol Med. 2006;35:292-300.

31. Brooks MN, Wang J, Li Y, Zhang R, Elashoff D, Wong DT. Salivary protein factors are elevated in breast cancer patients. Mol Med Rep. 2008;1:375-8.

32. Agha-Hosseini F, Mirzaii-Dizgah I, Rahimi A. Correlation of serum and salivary CA15-3 levels in patients with breast cancer. Med Oral Patol Oral Cir Bucal. 2009;14:521-4.

33. Sugimoto M, Wong DT, Hirayama A, Soga T, Tomita M. Capillary electrophoresis mass spectrometry-based saliva metabolomics identified oral, breast and pancreatic cancer-specific profiles. Metabolomics. 2010;6:78-95.

34. Rao PV, Reddy AP, Lu X, Dasari S, Krishnaprasad A, Biggs E et al. Proteomic identification of salivary biomarkers of type-2 diabetes. J Proteome Res. 2009;8:239-45.

35. Pandeshwar P, Das R. Role of oral fluids in DNA investigations. J Forensic Leg Med. 2014;22:45-50.

36. Valentini A, Miquel C, Nawaz MA, Bellemain E, Coissac E, Pompanon $\mathrm{F}$ et al. New perspectives in diet analysis based on DNA barcoding and parallel pyrosequencing: the trnL approach. Mol Ecol Resour. 2009;9:51-60.

37. Vivacqua G, Suppa A, Mancinelli R, Belvisi D, Fabbrini A, Costanzo M, et al. Salivary alpha-synuclein in the diagnosis of Parkinson's disease and Progressive Supranuclear Palsy. Parkinsonism Relat Disord. 2019;63:143-8.

38. Marksteiner J, Oberacher H, Humpel C. Acyl-Alkyl Phosphatidlycholines are Decreased in Saliva of Patients with Alzheimer's Disease as Identified by Targeted Metabolomics. J Alzheimers Dis. 2019;68:583-89. 
39. Julious SA. Sample sizes for clinical trials with normal data. Stat Med. 2004;23:1921-86.

40. Pu D, Liang H, Wei F et al. Evaluation of a novel saliva-based epidermal growth factor receptor mutation detection for lung cancer: A pilot study. Thorac Cancer. 2016;7:428-36.

41. Julious SA. Sample size of 12 per group rule of thumb for a pilot study. Pharmaceut Statist. 2005;4:287-91.

42. Faggion CM Jr. Evaluating the Risk of Bias of a Study. J Evid Based Dent Pract. 2015;15:164-70.

43. Ferlay J, Soerjomataram I, Dikshit R, Eser S, Mathers C, Rebelo $\mathrm{M}$, et al. Cancer incidence and mortality worldwide: sources, methods and major patterns in GLOBOCAN 2012. Int J Cancer. 2015;136:359-86.

44. Torre LA, Bray F, Siegel RL, Ferlay J, Lortet-Tieulent J, Jemal A. Global cancer statistics, 2012. CA Cancer J Clin. 2015;65:87-108.

45. Layke JC, Lopez PP. Gastric Cancer: Diagnosis and Treatment Options. Am Fam Physician. 2004;69:1133-40.

46. McGuigan A, Kelly P, Turkington RC, Jones C, Coleman HG, McCain RS. Pancreatic cancer: A review of clinical diagnosis, epidemiology, treatment and outcomes. World J Gastroenterol. 2018;24:4846-61.

47. Chen Y, Cheng S, Zhang A, Song J, Chang J, Wang K, et al. Salivary Analysis Based on Surface Enhanced Raman Scattering Sensors Distinguishes Early and Advanced Gastric Cancer Patients from Healthy Persons. J Biomed Nanotechnol. 2018;14:1773-84.

48. Shu J, Yu H, Du H, Zhang J, Zhang K, Li X. Identification of Nand O-linked glycans recognized by AAL in saliva of patients with atrophic gastritis and gastric cancer. Cancer Biomark. 2018;22:1-13. 49. Xiao H, Zhang Y, Kim Y, Kim S, Kim JJ, Kim KM, et al. Differential Proteomic Analysis of Human Saliva using Tandem Mass Tags Quantification for Gastric Cancer Detection. Sci Rep. 2016;6:22165. 50. Lee YH, Wong DT. Saliva: an emerging biofluid for early detection of diseases. Am J Dent. 2009;22:241-8.

51. Hong Z, Shi M, Chung KA, Quinn JF, Peskind ER, Galasko D, et al. DJ-1 and $\alpha$-synuclein in human cerebrospinal fluid as biomarkers of Parkinson's disease. Brain. 2010;133:713-26.

52. Scott DL, Wolfe F, Huizinga TWJ. Rheumatoid arthritis. Lancet. 2010;376:1094-108.

53. Javaid MA, Ahmed AS, Durand R, Tran SD. Saliva as a diagnostic tool for oral and systemic diseases. J Oral Biol Craniofac Res. 2016;6:67-76.

54. Xiao H, Zhang L, Zhou H, Lee JM, Garon EB, Wong DT. Proteomic analysis of human saliva from lung cancer patients using twodimensional difference gel electrophoresis and mass spectrometry. Mol Cell Proteomics. 2012;11:M111.012112.

55. Lee YH, Kim JH, Zhou H, Kim BW, Wong DT. Salivary transcriptomic biomarkers for detection of ovarian cancer: for serous papillary adenocarcinoma. J Mol Med. 2012;90:427-34.

56. Zhang L, Xiao H, Karlan S, Zhou H, Gross J, Elashoff D, et al. Discovery and preclinical validation of salivary transcriptomic and proteomic biomarkers for the non-invasive detection of breast cancer. PLoS One. 2010;5:e15573.

57. Li X, Yang T, Lin J. Spectral analysis of human saliva for detection of lung cancer using surface-enhanced Raman spectroscopy. J Biomed Opt. 2012;17:037003.

58. De Abreu Pereira D, Areias VR, Franco MF, Benitez MC, do Nascimento CM, de Azevedo CM, et al. Measurement of HER2 in saliva of women in risk of breast cancer. Pathol Oncol Res. 2013;19:509-13. 59. Chen D, Song N, Ni R, Zhao J, Hu J, Lu Q, et al. Saliva as a sampling source for the detection of leukemic fusion transcripts. J Transl Med. 2014;12:321.

60. Cheng F, Wang Z, Huang Y, Duan Y, Wang X. Investigation of salivary free amino acid profile for early diagnosis of breast cancer with ultra performance liquid chromatography-mass spectrometry. Clin Chim Acta. 2015;447:23-31.

61. Humeau M, Vignolle-Vidoni A, Sicard F, Martins F, Bournet B, Buscail L. Salivary MicroRNA in Pancreatic Cancer Patients. PLoS One. 2015;10:e130996.

62. Yan X, Yang M, Liu J, Gao R, Hu J, Li J, et al. Discovery and validation of potential bacterial biomarkers for lung cancer. Am J Cancer Res. 2015;5:3111-22.

63. Delmonico L, Moreira Ados S, Franco MF, Esteves EB, Scherrer L, Gallo CV, et al. CDKN2A (p14(ARF)/p16(INK4a)) and ATM promoter methylation in patients with impalpable breast lesions. Hum Pathol. 2015;46:1540-7.

64. Takayama T, Tsutsui H, Shimizu I, Toyama T, Yoshimoto N, Endo Y, et al. Diagnostic approach to breast cancer patients based on target metabolomics in saliva by liquid chromatography with tandem mass spectrometry. Clin Chim Acta. 2016;452:18-26.

65. Torres PJ, Fletcher EM, Gibbons SM, Bouvet M, Doran KS, Kelley ST. Characterization of the salivary microbiome in patients with pancreatic cancer. PeerJ. 2015;3:e1373.

66. Wood N, Streckfus CF. The Expression of Lung Resistance Protein in Saliva: A Novel Prognostic Indicator Protein for Carcinoma of the Breast. Cancer Invest. 2015;33:510-5.

67. Tsutsui H, Mochizuki T, Inoue K, Toyama T, Yoshimoto N, Endo Y, et al. High-throughput LC-MS/MS based simultaneous determination of polyamines including $\mathrm{N}$-acetylated forms in human saliva and the diagnostic approach to breast cancer patients. Anal Chem. 2013;85:11835-42.

68. Xie Z, Chen X, Li J, Guo Y, Li H, Pan X, et al. Salivary HOTAIR and PVT1 as novel biomarkers for early pancreatic cancer. Oncotarget. 2016;7:25408-19.

69. Zhong L, Cheng F, Lu X, Duan Y, Wang X. Untargeted saliva metabonomics study of breast cancer based on ultra performance liquid chromatography coupled to mass spectrometry with HILIC and RPLC separations. Talanta. 2016;158:351-60.

70. Machida T, Tomofuji T, Maruyama T, Yoneda T, Ekuni D, Azuma $\mathrm{T}$ et al. miR-1246 and miR-4644 in salivary exosome as potential biomarkers for pancreatobiliary tract cancer. Oncol Rep. 2016;36:2375-81.

71. Liu HJ, Guo YY, Li DJ. Predicting novel salivary biomarkers for the detection of pancreatic cancer using biological feature-based classification. Pathol Res Pract. 2017;213:394-99.

72. Bel'skaya L. The activity of metabolic enzymes in the saliva of lung cancer patients. Natl J Physiol Pharm Pharmacol. 2017;7:646-53. 73. Sun Y, Liu S, Qiao Z, Shang Z, Xia Z, Niu X, et al. Systematic comparison of exosomal proteomes from human saliva and serum for the detection of lung cancer. Anal Chim Acta. 2017;982:84-95.

74. Laidi F, Bouziane A, Errachid A, Zaoui F. Usefulness of Salivary and Serum Auto-antibodies Against Tumor Biomarkers HER2 and MUC1 in Breast Cancer Screening. Asian Pac J Cancer Prev. 2016;17:335-9.

75. Hernández-Arteaga A, de Jesús Zermeño Nava J, KolosovasMachuca ES, Velázquez-Salazar J, et al. Diagnosis of breast cancer by analysis of sialic acid concentrations in human saliva by surfaceenhanced Raman spectroscopy of silver nanoparticles. Nano Res. 2017;10:3662-70.

76. Cavaco C, Pereira JAM, Taunk K, Taware R, Rapole S, Nagarajaram $\mathrm{H}$, et al. Screening of salivary volatiles for putative breast cancer discrimination: an exploratory study involving geographically distant populations. Anal Bioanal Chem. 2018;410:4459-68.

77. Zermeño-Nava JJ, Martínez-Martínez MU, Rámirez-de-Ávila AL, Hernández-Arteaga AC, García-Valdivieso MG, HernándezCedillo A, et al. Determination of sialic acid in saliva by means of surface-enhanced Raman spectroscopy as a marker in adnexal mass patients: ovarian cancer vs benign cases. J Ovarian Res. 2018;11:61. 78. Tajmul M, Parween F, Singh L, Mathur SR, Sharma JB, Kumar $\mathrm{S}$, et al. Identification and validation of salivary proteomic signatures for non-invasive detection of ovarian cancer. Int J Biol Macromol. 2018;108:503-14.

79. Zhang J, Zhong Y, Zhang P, Du H, Shu J, Liu X, et al. Identification of abnormal fucosylated-glycans recognized by LTL in saliva of HBV-induced chronic hepatitis, cirrhosis, and hepatocellular carcinoma. Glycobiology. 2019;29:242-59.

80. Xie Z, Zhou F, Yang Y, Li L, Lei Y, Lin X, et al. Lnc-PCDH9-13:1 Is a Hypersensitive and Specific Biomarker for Early Hepatocellular Carcinoma. EBioMedicine. 2018;33:57-67. 
81. Devic I, Hwang H, Edgar JS, Izutsu K, Presland R, Pan C, et al. Salivary $\alpha$-synuclein and DJ-1: potential biomarkers for Parkinson's disease. Brain. 2011;134:e178.

82. Tsuruoka M, Hara J, Hirayama A, Sugimoto M, Soga T, Shankle WR, et al. Capillary electrophoresis-mass spectrometry-based metabolome analysis of serum and saliva from neurodegenerative dementia patients. Electrophoresis. 2013;34:2865-72.

83. Al-Nimer MS, Mshatat SF, Abdulla HI. Saliva $\alpha$-Synuclein and A High Extinction Coefficient Protein: A Novel Approach in Assessment Biomarkers of Parkinson's Disease. N Am J Med Sci. 2014;6:633-7.

84. Liang Q, Zhang $\mathrm{T}$ and Jiang Y, et al. Metabolomics-Based Screening of Salivary Biomarkers for Early Diagnosis of Alzheimer's Disease. RSC Adv. 2015;5:96074-9.

85. Liang Q, Liu H, Li X, et al. High-throughput metabolomics analysis discovers salivary biomarkers for predicting mild cognitive impairment and Alzheimer's disease. RSC Adv. 2016;6:75499-504.

86. Yilmaz A, Geddes T, Han B, Bahado-Singh RO, Wilson GD, Imam K, et al. Diagnostic Biomarkers of Alzheimer's Disease as Identified in Saliva using 1H NMR-Based Metabolomics. Alzheimers Dis. 2017;58:355-9.

87. Ashton NJ, Ide M, Schöll M, Blennow K, Lovestone S, Hye A, et al. No association of salivary total tau concentration with Alzheimer's disease. Neurobiol Aging. 2018;70:125-7.

88. Cao Z, Wu Y, Liu G, Jiang Y, Wang X, Wang Z, et al. $\alpha$-Synuclein in salivary extracellular vesicles as a potential biomarker of Parkinson's disease. Neurosci Lett. 2019;696:114-20.

89. Song W, Kothari V, Velly AM, Cressatti M, Liberman A, Gornitsky $\mathrm{M}$, et al. Evaluation of salivary heme oxygenase-1 as a potential biomarker of early Parkinson's disease. Mov Disord. 2018;33:583-91.

90. Manconi B, Liori B, Cabras T, Vincenzoni F, Iavarone F, Lorefice $\mathrm{L}$, et al. Top-down proteomic profiling of human saliva in multiple sclerosis patients. J Proteomics. 2018;187:212-22.

91. Buduneli E, Mäntylä P, Emingil G, Tervahartiala T, Pussinen $\mathrm{P}, \mathrm{Bar}$ ş $\mathrm{N}$, et al. Acute myocardial infarction is reflected in salivary matrix metalloproteinase- 8 activation level. J Periodontol. 2011;82:716-25.

92. Silva DG, Stevens RH, Macedo JM, Hirata R, Pinto AC, Alves LM, et al. Higher levels of salivary MUC5B and MUC7 in individuals with gastric diseases who harbor Helicobacter pylori. Arch Oral Biol. 2009;54:86-90.

93. Mirzaii-Dizgah I, Riahi E. Salivary troponin I as an indicator of myocardial infarction. Indian J Med Res. 2013;138:861-5.

94. Adornetto G, Fabiani L, Volpe G, De Stefano A, Martini S, Nenna $\mathrm{R}$, et al. An electrochemical immunoassay for the screening of celiac disease in saliva samples. Anal Bioanal Chem. 2015;407:7189-96. 95. Gang Cao, Maowen Chen, Yuanxiang Chen, Zufang Huang, Jinyong Lin, Jia Lin, et al. A potential method for non-invasive acute myocardial infarction detection based on saliva Raman spectroscopy and multivariate analysis. Laser Phys. 2015;12:125702.

96. Giusti L, Sernissi F, Donadio E, et al. Salivary psoriasin (S100A7) correlates with diffusion capacity of carbon monoxide in a large cohort of systemic sclerosis patients. J Transl Med. 2016;14:262.

97. Lu C, Hou X, Li M., Wang L, Zeng P, Jia H, et al Detection of AMA-M2 in human saliva: Potentials in diagnosis and monitoring of primary biliary cholangitis. Sci Rep. 2017;7:796.

98. Moher D, Liberati A, Tetzlaff J, Altman DG. Preferred reporting items for systematic reviews and meta-analyses: the PRISMA statement. PLoS Med. 2009;6:e1000097.

Funding

None declared.

Conflict of interest

None declared. 